\title{
Risk factors for early colonization of mutans streptococci - a multiple logistic regression analysis in Swedish 1-year-olds
}

\author{
Ann Ingemansson Hultquist ${ }^{1 \dagger}$, Peter Lingström ${ }^{2 \dagger}$ and Mats Bågesund ${ }^{3,4^{*}+}$
}

\begin{abstract}
Background: Mutans streptococci (MS) are closely related to the development of dental caries and are usually established in the oral cavity during early childhood. The aim of the study was to identify factors associated with the presence of MS in Swedish 1-year-olds.

Methods: Parents completed a questionnaire on different caries-associated factors and an oral bacterial sample was collected from 1,050 (526 boys, 524 girls) 1-year-olds. Multiple logistic regression analyses were performed to identify risk factors for colonization with MS.

Results: MS were found in 27\% of the 1-year-olds with teeth. High or very high MS scores (2-3) were found in 72 (7\%) of the children. MS score was correlated to the number of erupted teeth $(p<0.001)$. No difference due to gender was found. Multiple logistic regression analysis showed that presence of bacteria was associated with: caries in a sibling, other beverages than water between meals, and more than 8 erupted teeth. High or very high MS scores (2-3) were associated with other beverages than water between meals, and more than 8 erupted teeth.
\end{abstract}

Conclusions: Number of teeth present, diet and family aspects were factors associated with presence of MS in 1-year-olds. To develop high or very high MS scores, the number of erupted teeth and dietary habits are important.

Keywords: Children, Dental caries, Food and beverages, Infants, Risk factors, Sibling, Streptococcus mutans, Toothbrushing, Tooth eruption

\section{Background}

A reduced caries incidence among children has been observed in the Nordic countries during the last decades $[1,2]$, but dental caries is still a severe problem for those who are affected.

Due to the short distance from the outer dental surface to the pulp in the primary teeth, the progression of dental caries can be fast in early childhood [3] and the risk for dental infection is obvious. The risk for spreading of dental infections due to caries disease, which in severe cases can cause life threatening conditions [4],

\footnotetext{
* Correspondence: mats.bagesund@lio.se

${ }^{\dagger}$ Equal contributors

${ }^{3}$ Center for Orthodontics and Pediatric Dentistry, Public Dental Service Östergötland, Folktandvården Druvan, SE-601 82 Norrköping, Sweden ${ }^{4}$ Division of Pediatrics, Department of Clinical and Experimental Medicine, Faculty of Health Sciences, Linköping University, SE-581 85 Linköping, Sweden

Full list of author information is available at the end of the article
}

makes it important to prevent dental caries at an early age. The problems associated with dental treatment in early childhood - related to the infant's inability to understand the necessity for dental treatment, the limited ability to cooperate to the often unpleasant dental treatment and the following risk for development of dental fear - makes it even more urgent to avoid the establishment of dental caries among the youngest children [5].

Several caries associated risk factors have previously been identified [6,7], among which the oral colonization of mutans streptococci (MS) is a factor closely related to the development of dental caries both among children and adults [7-11].

MS from dental plaque has been associated to dental caries in preschool children [12,13] and higher MS scores have been found correlated to the caries incidence both in 6- to 7-year-olds [14] and in preschool children [15]. Children with a higher MS score can therefore be considered 
to have a higher caries risk than those without colonization of MS or those with a lower MS score.

Although MS is not naturally present in the oral cavity from birth [16] colonization often begins around the time point when the first teeth erupt $[17,18]$. It has been shown that the timing of MS colonization in the oral cavity influences caries risk [19,20], it is therefore considered important to identify factors associated with oral MS colonization at an early age. The eruption of teeth has been considered as a contributing factor for the colonization of MS in the oral cavity $[17,18]$ and as the timing of eruption of teeth is similar among boys and girls [21,22] at the same time as studies have found a higher caries prevalence among boys [23], we found it interesting to evaluate how eruption of teeth and gender may influence the colonization of MS among infants.

Neglected tooth brushing is known to contribute to the growth of bacteria [24] and since oral hygiene routines are considered to be better among girls than among boys (at least among primary school children) [25], we found it relevant to evaluate the influence of tooth brushing and gender on the colonization of MS in the oral cavity.

The aim was to evaluate possible risk factors associated to early oral colonization of MS in 1-year-olds, and the more specific hypotheses were that: 1) MS is not present in the oral cavity before the first tooth erupts, and 2) boys have higher MS scores than girls at one-year of age.

\section{Methods}

\section{Patients}

All 1-year-old children who lived in the region served by the Public Dental Clinic Vidablick, Norrköping, Sweden, between 2001 and 2010 were invited to participate in the study. Dated invitations were sent by mail to the parents around the time point for the 1-year birthday of their child. Approximately 130 invitations were sent each year. Those who missed the appointment without cancelling received no new invitation while those who cancelled the visit in advance were rescheduled for a new appointment.

All children who had taken antibiotics within the previous 2 weeks were given a new appointment a few weeks later. Approval of the study was obtained from the Regional Ethical Review Board at Linköping University.

\section{Procedure}

A questionnaire on caries-associated and other pertinent factors was sent to parents together with an invitation to the clinic. Parents were informed not to brush the child's teeth the morning before the visit. Informed consent was obtained from participating parents or legal guardians.

The questionnaire (Table 1) was completed by the parents. After answering the questionnaire and clinical
Table 1 Items from the questionnaire and abbreviations

\begin{tabular}{ll}
\hline Item & Abbreviation \\
\hline Does the child have any siblings? & Sibling \\
Have any of the siblings had dental caries? & Caries in sibling \\
$\begin{array}{l}\text { Does the child eat or drink anything except } \\
\text { water at night? }\end{array}$ & Night meal \\
Is the child still breastfed? & Breastfed \\
$\begin{array}{l}\text { Does the child have any illness/disease? } \\
\text { Does the child regularly take }\end{array}$ & Disease \\
$\begin{array}{l}\text { any medication? } \\
\text { Does the child drink anything } \\
\text { except water between the meals? }\end{array}$ & Medication \\
How many teeth does the child have? & Beverage other than water \\
Do you brush the child's teeth? & No tooth brushing \\
\hline
\end{tabular}

sampling, parents received information on oral health including how to avoid dental caries and how to handle dental trauma.

A visual inspection of the front teeth was done to evaluate visible signs of dental plaque. One bacterial sample per child was collected using a Quick-Stick ${ }^{\odot}$ (Dentsolv AB, Saltsjö-Boo, Sweden). If any tooth had erupted, the sample was taken from the buccal tooth surface/s of the (preferably maxillary) incisors close to the marginal gingival sulcus. If no teeth had erupted, the sample was taken from the tongue and cheek. Plaque on the Quick-Stick was transferred to an incubation strip (Dentocult ${ }^{\odot}$ Strip Mutans test; Orion Diagnostica, Espoo, Finland) and cultivated according to the manufacturer's instructions The sample was incubated in a heat chamber (Memmert $\mathrm{GmbH}$, Hannover, Germany) at the clinic for 48 hours at $37^{\circ} \mathrm{C}$ and then analyzed. The numbers of adherent colonies were compared with a chart supplied by the manufacturer and given a score between 0 and 3 to indicate low to high levels of MS (Table 2). An MS score of 0 included all MS bacterial samples with less than $10^{4} \mathrm{CFU} / \mathrm{ml}$.

Only one dental hygienist or dental assistant was present at each visit. Altogether four persons (one dental assistant with more than 30 years' experience and three dental hygienists with more than 3 years' experience) handled the information and collected the bacterial samples throughout the study.

\section{Statistical analyses}

Student's t-test and chi-square analysis was used for comparison of groups depending on whether the variables were continuous or categorical. The Spearman rank correlation analysis was used to analyze categorical data and continuous variables. In the multiple logistic regression analysis the variables were dichotomized before inclusion in the analysis. Multiple logistic regression analysis was performed to identify which variables were associated to 
Table 2 Characteristics of the 1-year-olds and possible difference between the genders

\begin{tabular}{|c|c|c|c|c|}
\hline Value & $\begin{array}{c}\text { Boys } \\
N=526\end{array}$ & $\begin{array}{c}\text { Girls } \\
N=524\end{array}$ & $\begin{array}{l}\text { Total/all } \\
N=1,050\end{array}$ & $\begin{array}{c}\text { Difference } \\
\text { p-value }\end{array}$ \\
\hline Age at visit (months; mean \pm S.D.) & $13.4 \pm 1.5$ & $13.6 \pm 2.0$ & $13.5 \pm 1.8$ & $0.11^{\alpha}$ \\
\hline Age range: min-max (months) & $11-20$ & $11-21$ & $11-21$ & \\
\hline Number of teeth (mean \pm S.D.) & $8.3 \pm 4.0$ & $7.8 \pm 4.2$ & $8.0 \pm 4.1$ & $0.04^{\alpha}$ \\
\hline Number of teeth (range) & $0-20$ & $0-20$ & $0-20$ & \\
\hline MS growth & $150(29 \%)$ & $138(26 \%)$ & $288(27 \%)$ & $0.43^{\text {ax }}$ \\
\hline \multicolumn{5}{|l|}{ MS score: } \\
\hline $0\left(<10^{4} \mathrm{CFU}^{\#} / \mathrm{ml}\right)$ & $394(75 \%)$ & $394(75 \%)$ & $788(75 \%)$ & $0.8095^{\mathrm{px}}$ \\
\hline $1\left(>10^{4}<10^{5} \mathrm{CFU}^{\#} / \mathrm{ml}\right)$ & $95(18 \%)$ & $95(18 \%)$ & $190(18 \%)$ & \\
\hline $2\left(>10^{5}<10^{6} \mathrm{CFU}^{\#} / \mathrm{ml}\right)$ & $23(4 \%)$ & $23(4 \%)$ & $46(4 \%)$ & \\
\hline $3\left(>10^{6} \mathrm{CFU}^{\#} / \mathrm{ml}\right)$ & $14(3 \%)$ & $12(2 \%)$ & $26(2 \%)$ & \\
\hline
\end{tabular}

\#CFU = colony-forming unit.

Statistical significance of difference was evaluated using:

${ }^{\text {oS}}$ Student's $t$-test for continuous variables.

${ }^{\text {ax }}$ Chi-square test for comparison of proportions.

the presence of MS or to high or very high (2-3) MS score. A p-value $<0.05$ was considered statistically significant. All statistical analyses were done with Stata/MP (version 12.1, StataCorp LP, College Station, TX 77845, USA).

\section{Results}

\section{Study group}

Parents of 1,121 children (566 boys, 555 girls) accepted the invitation and visited the clinic. The parents of 44 children ( 23 boys, 21 girls) did not complete the questionnaire. In another 27 (13 boys, 14 girls) children, the bacterial test could not be completed. Thus, only subjects with complete information were included in the further analyses. Children without siblings were included in the analysis.

Table 2 presents characteristics of the 1,050 (526 boys, 524 girls) children who completed the questionnaire and bacterial test. Despite the finding that the boys had a higher number of erupted teeth than the girls, the age of the children did not differ significantly between the genders (Table 2).

\section{Presence of mutans streptococci}

MS growth was found in 288 (27\%) of the 1,050 children. Table 3 lists the factors associated with a presence of bacteria according to the chi-square test. MS was significantly $(\mathrm{p}<0.05)$ more often present in the oral cavity among the 1,033 children with erupted teeth $(28 \%)$ than among the 17 children without erupted teeth (6\%). Only 1 of the 17 children with no erupted teeth presented any growth of MS. Presence of MS was significantly $(\mathrm{p}<$ 0.01 ) more frequently found among the 342 children with more than 8 teeth erupted $(33 \%)$ than among the 708 children who had fewer than 8 teeth erupted (25\%). No significant difference for MS in relation to gender was found (Table 2). Other factors associated with the presence of MS were caries in sibling $(\mathrm{p}<0.01)$, intake of other beverage than water between the meals $(\mathrm{p}<0.001)$ (Table 3). According to the multiple logistic regression analysis, the variables caries in sibling $(\mathrm{p}<0.05)$, other beverage than water between the meals $(\mathrm{p}<0.001)$, and more than 8 erupted teeth $(\mathrm{p}<0.05)$ were factors associated with the presence of MS (Table 4).

\section{MS score}

A high or very high MS score occurred in 72 (7\%) of all examined children (Table 2). Factors associated with a high or very high MS score according to the chi-square test were caries in sibling $(\mathrm{p}<0.01)$, night meal ( $\mathrm{p}<$ $0.01)$, other beverage than water between the meals $(\mathrm{p}<0.01)$ and more than 8 erupted teeth $(\mathrm{p}<0.01)$ (Table 3). According to the multiple logistic regression analysis (Table 5) association with a high or very high MS score (2-3) was found for other beverage than water between the meals $(\mathrm{p}<0.05)$, and more than 8 erupted teeth $(\mathrm{p}<0.01)$.

The MS score was relatively low (MS score 1 ) in the child who presented MS growth of bacteria before eruption of the first tooth. Table 5 lists results from the multiple logistic regression analysis of variables associated with a high or very high MS score (2-3). The Spearman rank correlation test found a correlation between number of teeth and MS score ( $\mathrm{p}<0.001$, Spearman's rho $=0.1062$ ).

Most of the variables that were significantly associated with the presence of MS or with a high or very high MS score in the chi-square test (Table 3) were also significant in the multiple logistic regression analyses (Tables 4 and 5). 
Table 3 Chi-square analysis of factors possibly associated to oral mutans streptococci in 1-year-olds

\begin{tabular}{|c|c|c|c|c|c|}
\hline \multirow{2}{*}{ Value } & \multirow{2}{*}{$\begin{array}{l}\text { Positive/number of observations } \\
\qquad(N=1,050)\end{array}$} & \multicolumn{2}{|c|}{ Chi-square test MS growth } & \multicolumn{2}{|c|}{ Chi-square test MS score $2-3$} \\
\hline & & (N) & p-value & (N) & p-value \\
\hline Caries in sibling $^{*}$ & $114 / 576$ & $(42)$ & 0.003 & (12) & 0.01 \\
\hline Caries in sibling $^{* *}$ & $114 / 1050$ & (44) & 0.02 & (32) & 0.10 \\
\hline Night meal & $338 / 1040$ & (95) & 0.65 & (33) & 0.01 \\
\hline Breastfed & $121 / 1048$ & (37) & 0.40 & (12) & 0.16 \\
\hline Disease & $32 / 1050$ & (9) & 0.93 & $(2)$ & 0.89 \\
\hline Medication & $21 / 1045$ & (8) & 0.26 & (1) & 0.70 \\
\hline Beverage other than water & 295/1038 & (108) & $<0.001$ & (32) & 0.002 \\
\hline$>0$ erupted teeth & $1033 / 1050$ & $(287)$ & 0.04 & (72) & 0.26 \\
\hline$>8$ erupted teeth & $342 / 1050$ & $(112)$ & 0.007 & (34) & 0.006 \\
\hline No tooth brushing & $63 / 1050$ & (23) & 0.096 & (7) & 0.17 \\
\hline
\end{tabular}

"Only children who had siblings.

${ }^{* *}$ All children, whether or not they had siblings.

Factors associated with the presence of mutans streptococci (MS) and with high or very high (2-3) MS score in 1-year-olds according to Chi-square test.

For explanation of the abbreviations of the values, see Table 1.

\section{Discussion}

\section{Study group}

The socioeconomic status of the population living in the region served by the Public Dental Clinic where the study was performed is considered to be representative for the region. From the population distribution in this area, about $85 \%$ of the invited children aged around 1 year participated. According to instructions from the Swedish Ethical Boards "it must be clarified that participation in research projects is voluntary and that one is entitled to withdraw at any moment without giving any explanation" [26]. We did therefore not investigate reasons for drop out. One reason for non-attendance at the 1-year appointment may be that parents, who had previously attended a 1-year-appointment with an older child where caries risk had been assessed to be low, may have considered it less important to attend a second appointment with their younger child, since the focus of the visit was information.

Table 4 Multiple logistic regression analysis to analyze factors possibly associated to the presence of mutans streptococci in 1-year-olds $(\mathrm{N}=1,038)$

\begin{tabular}{llll}
\hline Value & Odds ratio & $\mathbf{9 5 \% ~ C l}$ & $\mathbf{p}$-value \\
\hline Caries in sibling & 1.60 & $1.05-2.45$ & 0.028 \\
Night meal & 0.97 & $0.70-1.34$ & 0.85 \\
Breastfed & 1.21 & $0.76-1.92$ & 0.42 \\
Disease & 0.78 & $0.30-2.00$ & 0.60 \\
Medication & 1.64 & $0.54-4.99$ & 0.38 \\
Beverage other than water & 1.75 & $1.30-2.37$ & $<0.001$ \\
>0 erupted teeth & 7.68 & $0.95-62.34$ & 0.056 \\
> e erupted teeth & 1.44 & $1.07-1.94$ & 0.015 \\
No tooth brushing & 1.62 & $0.88-2.99$ & 0.12 \\
\hline
\end{tabular}

For an explanation of the abbreviations of the values, see Table 1.
A lower attendance rate at the dental clinic has been found to be higher in families with for example low socioeconomic status [27], language problems, or parental dental fear $[28,29]$. This study did not include socioeconomic status, immigrant background, parents' dental fear or parents' level of MS in the evaluation. This should be considered when interpreting the results from the study.

\section{Data collection procedure}

The four experienced professionals who collected the bacterial samples and other data all had the same information and collected the data in a standardized manner. The four professionals were calibrated regarding examination procedures and bacterial sample evaluation. Bacterial sample cultivation was performed according to the manufacturer's instructions. Since the start of the study, other published studies have argued for relevance of including samples from the tongue for the detection of

Table 5 Multiple logistic regression analysis of factors possibly associated with high or very high (2-3) mutans streptococci score in 1-year-olds $(\mathrm{N}=1,028)^{*}$

\begin{tabular}{llll}
\hline Value & Odds ratio & $\mathbf{9 5 \%} \mathbf{C l}$ & p-value \\
\hline Caries in sibling & 1.37 & $0.70-2.70$ & 0.35 \\
Night meal & 1.66 & $0.98-2.82$ & 0.061 \\
Breastfed & 1.23 & $0.60-2.54$ & 0.57 \\
Disease & 0.78 & $0.15-4.01$ & 0.76 \\
Medication & 0.71 & $0.07-6.79$ & 0.77 \\
Beverage other than water & 1.91 & $1.16-3.14$ & 0.011 \\
$>$ 8 erupted teeth & 2.06 & $1.25-3.40$ & 0.005 \\
No tooth brushing & 1.57 & $0.67-3.73$ & 0.30
\end{tabular}

${ }^{¥}$ Including children who had no siblings.

None of the pre-dentate children had a high or very high MS score, why the variable ( $>0$ erupted teeth) was excluded from the analysis. For an explanation of the abbreviations of the values, see Table 1. 
MS [30]. We anyhow decided to continue our data collection as planned since the start of the study with sampling from teeth, and only if no teeth were erupted the sample was taken from the tongue and cheek, as described in the Methods section.

\section{Presence of mutans streptococci}

The finding that $73 \%$ of the 1-year-old children not exhibited any MS growth while $75 \%$ of the children with positive findings had an MS score of 0 (Table 2) is explained by the definition of the MS score 0 , which includes all MS bacterial samples with less than $10^{4} \mathrm{CFU} / \mathrm{ml}$ (Table 2), according to instructions from the manufacturer.

Even if the major intra-familial transmission of bacteria is vertical [31], the finding that the variable caries in sibling was associated with presence of MS is supported by previous findings of horizontal transmission of MS between unrelated preschool children [32-34]. Thus, the association between growth of MS at 1-years-age and caries in sibling found in our study could be the result of horizontal transmission [32,34] from a sibling or by vertical transmission from the mother or father to the child [31], or a combination of these two. A previous study [34] supports the possibility for different ways for transmission of MS.

The association of high or very high (2-3) MS score with the variables night meal (according to the Chisquare test) and consumption of beverages other than water between meals (according to both Chi-square test and multiple regression analysis) are in agreement with Thorild et al. [35], who found that daily intake of candy and sugar drinks between meals in feeding bottles were associated with MS prevalence in children aged 1.5 and 3 years. These findings are also in agreement with the findings of Grindefjord et al. [8], who performed a study on MS among 1000 1-year-old children in the Stockholm area, and found an association between the presence of MS and sugar-containing beverages at night and total consumption of sugar-containing beverages at 1-years-age. Our finding that no tooth brushing was not significantly associated with the presence of MS is in contrast to the results presented by Zhou et al. [36], who found that colonization of MS in 8 to 32-month-old children was associated with poor oral hygiene [36].

\section{Tooth eruption and presence of MS}

The association found between tooth eruption and presence of MS in the Chi-square test (Table 3) agrees with previous findings where MS was cultivated from bacterial colonies sampled from the tongues of 1-year-olds [8]. This association was anyhow not significant in the multiple regression analysis, even if the odds ratio for erupted teeth was higher than for the other variables (Table 4). It has been postulated that MS is unable to colonize the oral cavity until part of the first primary tooth has erupted [37]. In our study, only one child presented growth of MS before eruption of the first tooth. Since the number of teeth were evaluated by the parents (in a questionnaire) and not in the clinical examination, it is possible that a minor part of a tooth had been exposed to the oral cavity before it was observed by the parents. Several studies, however, have shown that colonization of MS is possible also prior to eruption of a tooth surface $[18,29,38]$. The association between number of teeth and MS score and the finding that more than 8 erupted teeth made MS colonization more frequent is probably due to the larger tooth surface area available for MS colonization in a more developed dentition. This is particularly evident when the primary molars have erupted $[8,39]$. It's also possible that the time since the first tooth erupted (age of the child) rather than the presence or absence of teeth could have contributed to some of the differences found regarding MS colonization between the groups of children with different number of teeth erupted. The first hypothesis that MS is not present in the oral cavity before the first tooth erupts - was rejected, since it was possible to identify MS before eruption of the first tooth. It can be discussed whether the 17 pre-dentate children should have been excluded from the study, since they had no erupted teeth and the sampling in these patients were performed from the oral mucosa instead of from the tooth surface. Excluding the pre-dentate children would have made evaluation of the first hypothesis impossible. A complementary analysis of the results excluding the 17 predentate children, anyhow, resulted in almost identical results, why we decided to include them in the analysis.

The finding that no tooth brushing was not significantly associated to presence of MS in the multiple logistic regression analysis is in contrast to other studies on preschool children both before [22] and after 1years-age [40].

\section{MS score}

The finding that $7 \%$ of the samples from 1-year-old children in the present study had a high or very high MS score (2-3) is in agreement with the findings of Grindefjord et al. [8] who found a high or very high MS score in bacterial samples from the tongue among $6 \%$ of 1 -year-olds in the Stockholm area.

The finding that the boys had a higher number of erupted teeth than the girls is not supported by previous studies among Swedish [21] and Finnish children [22] where the mean age at the eruption of the first primary tooth was similar for the boys and the girls. But even if the number of erupted teeth in our study was higher among the boys, no significant difference regarding MS score was found between the boys and the girls. This study did not focus on the time since eruption, which 
may be of higher importance. The second hypothesis that boys have higher MS scores than girls at one-year age - was rejected.

The findings from the present study are important for all health professionals, who are interested in the multifactorial etiology of MS colonization of the oral cavity. It will provide a better knowledge and possible implications for the clinician, who wants to provide a better preventive dental care to avoid dental caries in pre-school children.

\section{Conclusions}

Factors associated both with the presence of MS and with a high or very high MS score at 1-years-age are caries in a sibling, consumption of beverages other than water between meals, and more than 8 erupted teeth. The number of erupted teeth, dietary habits and family factors are important for the colonisation of MS in the oral cavity.

\section{Abbreviations}

MS: Mutans streptococci; CFU: Colony-forming unit.

\section{Competing interests}

The authors declare that they have no competing interests.

\section{Authors' contributions}

AlH participated in the design of the study, in acquisitioning of data and in writing of the manuscript. PL participated in the design of the study and in writing the manuscript. MB participated in the design of the study, statistical analyses and in writing the manuscript. All authors approved the final version of the manuscript.

\section{Acknowledgements}

Thanks to personnel at the Public Dental Clinic Vidablick, Norrköping, for valuable support.

Thanks to statistician Mats Fredrikson, LARC, Linköping, for statistical advice. The study was supported by the Public Dental Service/Folktandvården Östergötland, Sweden.

\section{Author details}

${ }^{1}$ Public Dental Service/Folktandvården, Stora Trädgårdsgatan 39, SE-593 42 Västervik, Sweden. ${ }^{2}$ Department of Cariology, Institute of Odontology, Sahlgrenska Academy, University of Gothenburg, Box 450SE-405 30 Göteborg, Sweden. ${ }^{3}$ Center for Orthodontics and Pediatric Dentistry, Public Dental Service Östergötland, Folktandvården Druvan, SE-601 82 Norrköping, Sweden. ${ }^{4}$ Division of Pediatrics, Department of Clinical and Experimental Medicine, Faculty of Health Sciences, Linköping University, SE-581 85 Linköping, Sweden.

Received: 11 August 2014 Accepted: 10 November 2014 Published: 3 December 2014

\section{References}

1. Hugoson A, Koch G, Helkimo AN, Lundin SA: Caries prevalence and distribution in individuals aged 3-20 years in Jönköping, Sweden, over a 30-year period (1973-2003). Int J Paediatr Dent 2008, 18:18-26.

2. Stecksén-Blicks C, Kieri C, Nyman JE, Pilebro C, Borssén E: Caries prevalence and background factors in Swedish 4-year-old children - a 40-year perspective. Int J Paediatr Dent 2008, 18:317-324.

3. Colak H, Dujgeril CT, Dalli M, Hamidi MM: Early childhood caries update: a review of causes, diagnoses, and treatments. J Nat Sci Biol Med 2013, 4:29-38.

4. Casamassimo PS, Thikkurissy S, Edelstein BL, Maiorini E: Beyond the dmft: the human and economic cost of early childhood caries. J Am Dent Assoc 2009, 140:650-657.

5. Klingberg G, Berggren U, Carlsson SG, Noren JG: Child dental fear: causerelated factors and clinical effects. Eur J Oral Sci 1995, 103:405-412.
6. Featherstone JD: The continuum of dental caries-evidence for a dynamic disease process. J Dent Res 2004, 83(Spec No C):C39-C42.

7. Takahashi N, Nyvad B: The role of bacteria in the caries process: ecological perspectives. J Dent Res 2011, 90:294-303.

8. Grindefjord M, Dahllöf G, Wikner S, Hojer B, Modéer T: Prevalence of mutans streptoccus in one-year-old children. Oral Microbiol Immunol 1991, 6:280-283.

9. Grindefjord M, Dahllöf G, Nilsson B, Modéer T: Prediction of dental caries development of 1-year- old children. Caries Res 1995, 29:343-348.

10. Hamada S, Slade HD: Biology, immunology, and cariogenicity of Streptococcus mutans. Microbiol Rev 1980, 44:331-384.

11. Ge Y, Caufield PW, Fisch GS, Li Y: Streptococcus mutans and Streptococcus sanguinis colonization correlated with caries experience in children. Caries Res 2008, 42:444-448.

12. Alaluusua S, Renkonen OV: Streptococcus mutans establishment and dental caries experience in children from 2 to 4 years old. Scand J Dent Res 1983, 91:453-457.

13. Mitrakul $K$, Asvanund $Y$, Vongsavan K: Prevalence of five biofilm-related oral streptococci species from plaque. J Clin Pediatr Dent 2011, 36:161-166.

14. Splieth C, Bernhardt O: Prediction of caries development for molar fissures with semiquantitative mutans streptococci test. Eur J Oral Sci 1999, 107:164-169.

15. Meurman PK, Pienihäkkinen K: Factors associated with caries increment: a longitudinal study from 18 months to 5 years of age. Caries Res 2010, 44:519-524.

16. Kutsch VK, Young DA: New direction in the etiology of dental caries disease. J Calif Dent Assoc 2011, 10:716-721.

17. Tankkunnasombut $S$, Youcharoen K, Wisuttisak W, Vichayanrat $S$, Tiranathanagul $\mathrm{S}$ : Early colonization of mutans streptococci in 2- to 36-month-old Thai children. Pediatr Dent 2009, 31:47-51.

18. Florio FM, Klein MI, Pereira AC, Goncalves BR: Time of initial acquisition of mutans streptococci by human infants. I Clin Pediatr Dent 2004, 28:303-308.

19. Laitala M, Alanen $P$, Isokangas $P$, Söderling E, Pienihäkkinen K: A cohort study on the association of early mutans streptococci colonisation and dental decay. Caries Res 2012, 46:228-233.

20. Köhler B, Andréen I: Mutans streptococci and caries prevalence in children after early maternal caries prevention: a follow-up at 19 years of age. Caries Res 2012, 46:474-480.

21. Lysell L, Magnusson B, Thilander B: Time and order of eruption of the primary teeth. A longitudinal study. Odontol Revy 1962, 13:217-234.

22. Nyström M: Clinical eruption of deciduous teeth in a series of Finnish children. Proc Finn Dent Soc 1977, 73:155-161.

23. Peressini S, Leake JL, Mayhall JT, Maar M, Trudeau R: Prevalence of early childhood caries among First Nations children, District of Manitoulin, Ontario. Int J Paediatr Dent 2004, 4:101-110.

24. Plonka KA, Pukallus ML, Barnett AG, Walsh LJ, Holcombe TF, Seow WK: A longitudinal study comparing mutans streptococci and lactobacilli colonisation in dentate children aged 6 to 24 months. Caries Res 2012, 46:385-393

25. Halonen $H$, Pesonen $P$, Seppä L, Peltonen E, Tjäderhane L, Anttonen V: Outcome of a community-based oral health promotion project on primary schoolchildren's oral hygiene habits. Int J Dent 2013, 2013:485741 [http://dx.doi.org/10.1155/2013/485741]

26. Ahlgren AK: Central Ethical Review Board: Information to research persons. In [http://www.epn.se/media/50967/information_for_research_participants.pdf]

27. Crocombe LA, Broadbent JM, Thomson WM, Brennan DS, Poulton R: Impact of dental visiting trajectory patterns on clinical oral health and oral health-related quality of life. J Public Health Dent 2012, 72:36-44.

28. Ridell $\mathrm{K}$, Matsson L, Mejàre I: Background factors associated with endodontic treatment due to caries in young permanent teeth. Acta Odontol Scand 2007, 65:219-223.

29. Tanner AC, Milgrom PM, Kent R Jr, Mokeem SA, Page RC, Riedy CA, Weinstein $P$, Bruss J: The microbiota of young children from tooth and tongue samples. J Dent Res 2002, 81:53-57.

30. Doméjean S, Zhan L, DenBesten PK, Stamper J, Boyce WT, Featherstone JD: Horizontal transmission of mutans streptococci in children. J Dent Res 2010, 89:51-55.

31. Köhler B, Lundberg AB, Birkhed D, Papapanou PN: Longitudinal study of intrafamilial mutans streptococci ribotypes. Eur J Oral Sci 2003, 111:383-389.

32. Poureslami HR, Van Amerongen WE: Early childhood caries (ECC) an infectious transmissible oral disease. Indian J Pediatr 2009, 76:191-194. 
33. Mattos-Graner RO, Li Y, Caufield PW, Duncan M, Smith DJ: Genotypic diversity of mutans streptococci in Brazilian nursery children suggests horizontal transmission. J Clin Microbiol 2001, 39:2313-2316.

34. Redmo Emanuelsson IM, Wang X: Demonstration of identical strains of mutans streptococci within Chinese families by genotyping. Eur J Oral Sci 1998, 106:7887-7894.

35. Thorild I, Lindau-Jonson B, Twetman S: Prevalence of salivary Streptococcus mutans in mothers and in their preschool children. Int J Paediatr Dent 2002, $12: 2-7$.

36. Zhou Y, Yang J, Zhi Q, Tao Y, Qiu R, Lin H: Factors associated with colonization of Streptococcus mutans in 8-to 32-month-old children: a cohort study. Aust Dent J 2013, 58:507-513.

37. Eggertsson $\mathrm{H}$, Ferreira-Zandona A: Dentition and lesion history. In Detection, assessment, diagnosis and monitoring of caries, Volume 21. Edited by Pitts NB. Basel: Karger; Monogr Oral Sci; 2009:102-122.

38. Berlutti F, Catizone A, Ricci G, Frioni A, Natalizi T, Valenti P, Polimeni A: Streptococcus mutans and Streptococcus sobrinus are able to adhere and invade human gingival fibroblast cell line. Int I Immunopathol Pharmacol 2010, 23:1253-1260.

39. Tedjosasongko U, Kozai K: Initial acquisition and transmission of mutans streptococci in children at day nursery. ASDC J Dent Child 2002, 69:284-288. 234-235.

40. Law V, Seow WK: A longitudinal controlled study of factors associated with mutans streptococci infection and caries lesion initiation in children 21 to 72 months old. Pediatr Dent 2006, 28:58-65.

doi:10.1186/1472-6831-14-147

Cite this article as: Ingemansson Hultquist et al:: Risk factors for early colonization of mutans streptococci - a multiple logistic regression analysis in Swedish 1-year-olds. BMC Oral Health 2014 14:147.

\section{Submit your next manuscript to BioMed Central and take full advantage of:}

- Convenient online submission

- Thorough peer review

- No space constraints or color figure charges

- Immediate publication on acceptance

- Inclusion in PubMed, CAS, Scopus and Google Scholar

- Research which is freely available for redistribution 